\title{
Syntaxin-1 $\mathrm{N}$-peptide and $\mathrm{H}_{\mathrm{abc}}$-domain perform distinct essential functions in synaptic vesicle fusion
}

\author{
Peng Zhou ${ }^{1}$, Zhiping P Pang ${ }^{1,3}$, \\ Xiaofei Yang ${ }^{1}$, Yingsha Zhang ${ }^{1}$, \\ Christian Rosenmund ${ }^{2}$, Taulant Bacaj ${ }^{1}$ \\ and Thomas C Südhof ${ }^{1, *}$

\begin{abstract}
${ }^{1}$ Department of Molecular and Cellular Physiology, Howard Hughes Medical Institute, Stanford University School of Medicine, Stanford, CA, USA and ${ }^{2}$ NeuroCure Cluster of Excellence, Charité,

Universitätsmedizin, Berlin, Germany
\end{abstract}

Among SNARE proteins mediating synaptic vesicle fusion, syntaxin-1 uniquely includes an $\mathrm{N}$-terminal peptide (' $\mathrm{N}$ peptide') that binds to Munc18-1, and a large, conserved $\mathrm{H}_{\mathrm{abc}}$-domain that also binds to Munc18-1. Previous in vitro studies suggested that the syntaxin-1 $\mathrm{N}$-peptide is functionally important, whereas the syntaxin- $1 \mathrm{H}_{\mathrm{abc}}$-domain is not, but limited information is available about the in vivo functions of these syntaxin-1 domains. Using rescue experiments in cultured syntaxin-deficient neurons, we now show that the N-peptide and the $\mathrm{H}_{\mathrm{abc}}$-domain of syntaxin1 perform distinct and independent roles in synaptic vesicle fusion. Specifically, we found that the $\mathrm{N}$-peptide is essential for vesicle fusion as such, whereas the $\mathrm{H}_{\mathrm{abc}}$-domain regulates this fusion, in part by forming the closed syntaxin-1 conformation. Moreover, we observed that deletion of the $\mathrm{H}_{\mathrm{abc}}$-domain but not deletion of the $\mathrm{N}$-peptide caused a loss of Munc18-1 which results in a decrease in the readily releasable pool of vesicles at a synapse, suggesting that Munc18 binding to the $\mathrm{H}_{\mathrm{abc}}$-domain stabilizes Munc18-1. Thus, the N-terminal syntaxin-1 domains mediate different functions in synaptic vesicle fusion, probably via formation of distinct Munc18/SNARE-protein complexes.

The EMBO Journal (2013) 32, 159-171. doi:10.1038/ emboj.2012.307; Published online 27 November 2012 Subject Categories: membranes \& transport; neuroscience Keywords: membrane fusion; neurotransmitter release; SM proteins; synapse; syntaxin

\section{Introduction}

Synaptic vesicle fusion, like most intracellular membrane fusion, is mediated by the concerted action of two protein families, namely the SNARE (for 'soluble NSF attachment

\footnotetext{
*Corresponding author. Departments of Molecular \& Cellular Physiology, Neurology, and Psychiatry \& Behavioral Sciences, Stanford University School of Medicine, 265 Campus Drive, Stanford, CA 94305, USA. Tel.: +1 650721 1421; Fax: +1 650498 4585;

E-mail: tcs1@stanford.edu

${ }^{3}$ Present address: Child Health Institute of New Jersey, and Department of Neuroscience and Cell Biology, Robert Wood Johnson Medical School, New Brunswick, NJ 08901, USA
}

Received: 15 June 2012; accepted: 24 October 2012; published online: 27 November 2012 protein receptors') and SM (for 'Sec1-Munc18 like') protein families (reviewed in Rizo and Rosenmund, 2008; Sørensen, 2009; and Südhof and Rothman, 2009). In presynaptic terminals, the SNARE proteins syntaxin-1, SNAP-25, and synaptobrevin/VAMP form a tight complex composed of a four-helical bundle that forces membranes into close proximity, and that is acted upon by Munc18-1 to catalyse fusion (Südhof and Rothman, 2009). All SNARE proteins include a SNARE motif (an $\sim 60$ residue conserved sequence) that forms the SNARE complex and a membrane anchor (usually a transmembrane region) that attaches the SNARE proteins to membranes. Syntaxin-1 is remarkable among synaptic SNARE proteins in that it additionally contains a large N-terminal region that accounts for $\sim 60 \%$ of its total sequence. The syntaxin-1 N-terminal region is composed of two protein motifs: (i) a short $\mathrm{N}$-terminal peptide ('N-peptide') that binds to Munc18-1 (Dulubova et al, 2007; Hu et al, 2007; Rickman et al 2007) and (ii) a larger $\mathrm{H}_{\mathrm{abc}}$-domain that consists of an autonomously folded three-helical bundle (Fernandez et al, 1998; Antonin et al, 2002; Bracher and Weissenhorn, 2004). The $\mathrm{H}_{\mathrm{abc}}$-domain folds back onto the SNARE motif of syntaxin-1 to produce the 'closed' conformation of syntaxin-1 that also binds to Munc18-1 independent of the N-peptide (Hata et al, 1993; Dulubova et al, 1999; Misura et al, 2000; Rickman et al 2007). Thus, the two N-terminal syntaxin-1 sequence motifs both separately bind to Munc18-1-which is essential for synaptic vesicle fusion (Verhage et al, 2000)-by two different and independent mechanisms.

Many in vitro and in vivo studies demonstrated that Munc18-1 binding by the N-peptide of syntaxin-1 is essential for fusion (Khvotchev et al, 2007; Shen et al, 2007; Tareste et al, 2008; Deák et al, 2009; Johnson et al, 2009; Diao et al, 2010; Rathore et al, 2010; Schollmeier et al, 2011; Shi et al, 2011). A recent study, however, concluded that Munc18-1 binding to the syntaxin-1 N-peptide is not important because Munc18-1 mutants that show diminished binding to the $\mathrm{N}$-peptide were able to support fusion (Meijers et al, 2012). Although the mutants examined in that study still partly bind to the N-peptide, which may complicate the interpretation of the results, the Meijers et al (2012) paper illustrates that the role of the Munc18-1 binding to the syntaxin-1 N-peptide remains incompletely understood despite a large number of studies on its role.

In contrast to the $\mathrm{N}$-peptide, the physiological function of the $\mathrm{H}_{\mathrm{abc}}$-domain and of the closed conformation of syntaxin-1 that it forms has not been examined closely. The closed conformation of syntaxin-1 is formed by an intramolecular interaction of the $\mathrm{H}_{\mathrm{abc}}$-domain of syntaxin-1 with its SNARE motif, thereby occluding the SNARE motif. The closed conformation has to open prior to SNARE-complex formation, suggesting that the closed conformation inhibits fusion. Consistent with this notion, a point mutation in syntaxin-1 
(the 'LE mutation'; Dulubova et al, 1999) that shifts the default conformation of syntaxin-1 from 'closed' to 'open' causes an increase in spontaneous release and in the vesicular release probability (Gerber et al, 2008). Moreover, this mutation partly bypasses the requirement for Munc13 (an active zone protein unrelated to Munc18-1) in synaptic vesicle priming in C. elegans (Richmond et al, 2001), which agrees with the hypothesis that Munc13 functions by opening syntaxin-1 (Ma et al, 2011). Finally, the LE mutation decreases the levels of Munc18-1 in vivo and produces a decrease in the readily releasable pool (RRP) of vesicles, suggesting that Munc18-1 binding to the closed conformation of syntaxin-1 stabilizes Munc18-1 (Gerber et al, 2008), similarly to the stabilization of syntaxin-1 by Munc18-1 (Verhage et al, 2000). These in vivo studies therefore reveal an important but incompletely defined role for the closed conformation of synaxin-1 in regulating synaptic fusion. However, they do not reveal whether the $\mathrm{H}_{\mathrm{abc}}$-domain performs additional functions in fusion independent of its formation of the closed conformation of syntaxin-1. The only available information on this question is provided by in vitro studies documenting that the $\mathrm{H}_{\mathrm{abc}}{ }^{-}$ domain is dispensable for fusion as such (Rathore et al, 2010; Shen et al, 2010), but these studies do not show whether the $\mathrm{H}_{\mathrm{abc}}$-domain has a physiological function of its own.

Collectively, these observations thus suggest that the $\mathrm{N}$-peptide and the $\mathrm{H}_{\mathrm{abc}}$-domain of synaxin-1 perform distinct functions in synaptic vesicle fusion, but raise two major questions: first, is Munc18-1 binding to the N-peptide of syntaxin-1 indeed essential for fusion? If so, is it essential because the N-peptide stabilizes Munc18-1, Munc18-1 directly catalyses fusion, or Munc18-1 facilitates opening of syntaxin-1 and promotes SNARE-complex assembly? Second, does the $\mathrm{H}_{\mathrm{abc}}$-domain contribute to syntaxin function only by forming the closed conformation of syntaxin-1, or does it have other independent functions in synaptic vesicle fusion? To address these questions, we have now employed syntaxin1 knockdown (KD) experiments combined with rescue manipulations, and systematically explored the role of the $\mathrm{N}$-terminal syntaxin-1 sequences in synaptic vesicle fusion. Our data establish a role in synaptic fusion for both the $\mathrm{N}$-peptide mediated and the $\mathrm{H}_{\mathrm{abc}}$-domain mediated interaction of syntaxin-1 with Munc18-1, with the N-peptide being essential for fusion as such without contributing to the stabilization of Munc18-1, and the $\mathrm{H}_{\mathrm{abc}}$-domain regulating fusion at multiple junctures

\section{Results}

\section{Generation of syntaxin-deficient neurons}

Using lentiviral delivery of shRNAs into cultured cortical neurons (Pang et al, 2010; Yang et al, 2010), we tested the efficacy of shRNAs that target conserved synaxin-1 sequences, and measured the degree of syntaxin-1B KD by quantitative rt-PCR (Ko et al, 2011). These experiments identified two effective shRNAs that were then cloned into a single lentivirus that also allowed facultative co-expression of shRNA-resistant rescue constructs. We validated the KD efficiency of the lentivirus thus obtained in neurons from syntaxin-1A knockout (KO) mice (Gerber et al, 2008). The syntaxin-1 KD lentivirus suppressed syntaxin-1B mRNA levels by $\sim 90 \%$ (Figure 1A), and syntaxin-1B protein levels by $>60 \%$ in cultured syntaxin-1A KO neurons (Figure $1 \mathrm{~B}$ ).

To estimate the overall impact of the syntaxin-1 deficiency on neuronal integrity and synaptic function, we measured synapse densities in control and syntaxin-deficient neurons without or with co-expression of an shRNA-resistant syntaxin- $1 \mathrm{~A}$ as a rescue protein, but detected no major changes (Figure 1C).

We then examined whether the synaxin-1 deficiency impaired synaptic transmission and whether this phenotype is rescued by re-expression of synaxin-1A or $-1 \mathrm{~B}$ cDNAs that have been rendered insensitive to the shRNA by introduction of silent point mutations, and that were compared with each other to ensure that the two syntaxin-1 isoforms are functionally redundant. We monitored synaptic transmission by whole-cell patch-clamp recordings of cultured cortical neurons with an extracellular concentric stimulation electrode as calibrated in detail in previous studies (Maximov and Südhof, 2005; Maximov et al, 2007; Pang et al, 2010; Kaeser et al, 2011).

We found that the syntaxin-1 deficiency severely impaired synaptic transmission, monitored as inhibitory postsynaptic currents (IPSCs) induced either by isolated stimuli (Figure 1D) or $10 \mathrm{~Hz}$ stimulus trains (Figure 1E). Both syntaxin-1A and syntaxin-1B rescued these phenotypes, confirming their functional redundancy (Figures 1D and E). Thus, for all subsequent experiments we used syntaxin-1A KO neurons with the syntaxin-1B KD to achieve a maximal suppression of both major presynaptic syntaxin-1 isoforms (syntaxin-1A and -1B), and always included two controls: (i) a lentivirus that does not express an shRNA (generic control) and (ii) a lentivirus that expresses both the syntaxin-1B shRNA and a syntaxin-1A rescue protein whose synthesis was driven by a synapsin promoter and whose mRNA was rendered insensitive to the shRNA (rescue control, to control for off-target effects of shRNAs).

\section{The Munc18-1 binding site of the syntaxin-1 $\mathrm{H}_{\mathrm{abc}}$-domain but not of its $\mathrm{N}$-peptide is essential for chaperoning Munc18-1 levels}

In a first set of experiments to analyse the $\mathrm{N}$-terminal domains of syntaxin-1, we quantified the levels of selected proteins in syntaxin-1-deficient neurons without and with rescue with wild-type syntaxin-1A or two different mutants of syntaxin-1. We found that the syntaxin-1 deficiency caused a selective, large decrease in Munc18-1 levels that was rescued by wild-type syntaxin-1A (Figure 2). Strikingly, the decrease in Munc18-1 levels in syntaxin-deficient neurons was also fully rescued by mutant syntaxin-1A with a deletion of the $\mathrm{N}$-peptide (Synt1 $\mathrm{A}^{\Delta \mathrm{N}}$ ) which binds to and anchors Munc18-1 on assembling SNARE complexes (Figure 2A; Dulubova et al, 2007). However, the decrease in Munc18-1 levels was not rescued by syntaxin-1A lacking the $\mathrm{H}_{\mathrm{abc}}$-domain (Figure $2 \mathrm{~B}$ ). Thus, syntaxin-1 is required for maintaining normal Munc181 levels, just as Munc18-1 is required for maintaining normal syntaxin-1 levels (Verhage et al, 2000), and this function of syntaxin-1 requires the Munc18-1 binding site of the syntaxin-1 $\mathrm{H}_{\mathrm{abc}}$-domain domain (probably because this domain mediates the closed conformation of syntaxin-1; Gerber et al, 2008), but not the Munc18-1 binding site of the syntaxin-1 N-peptide. 
A
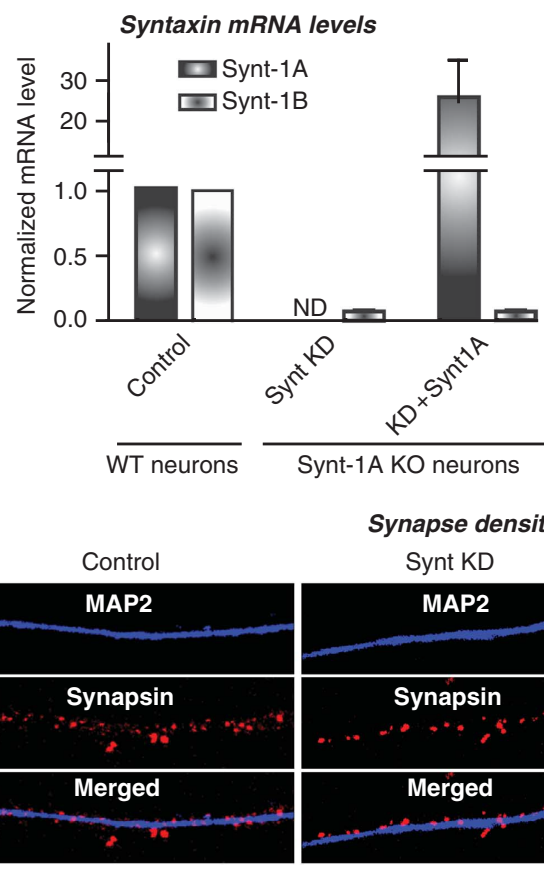

Synt-1A KO neurons

Synapse density
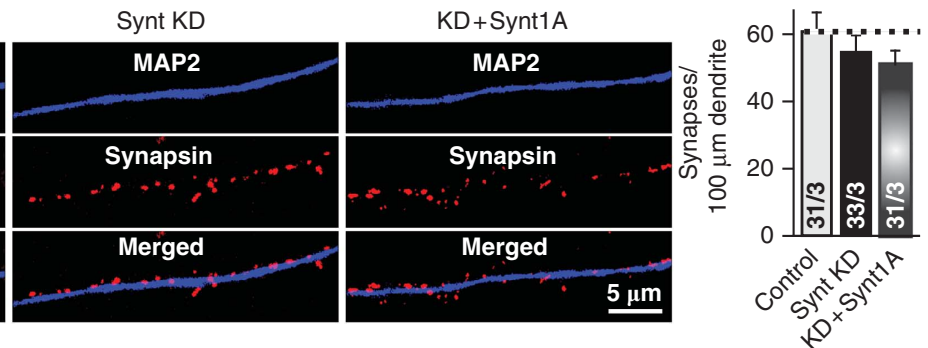

D

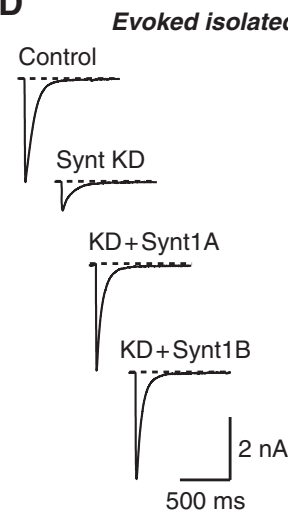

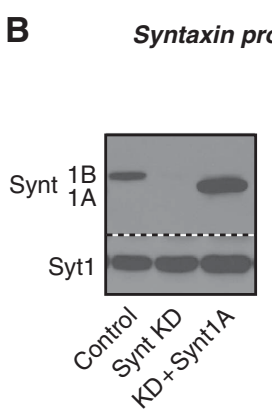

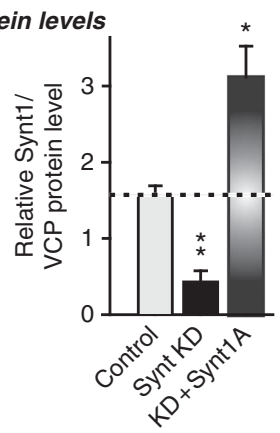

Synt-1A KO neurons
$\mathbf{E}$

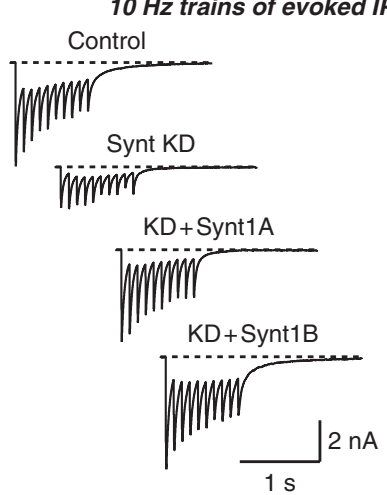

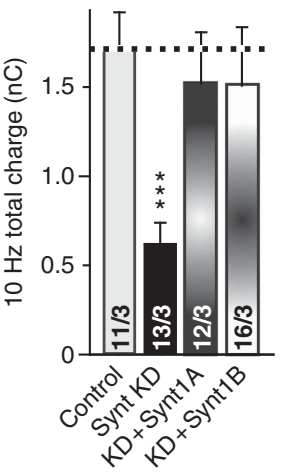

Figure 1 Characterization of syntaxin-1 knockdown (KD) neurons. (A) Summary graph of syntaxin-1A and -1B mRNA levels measured by quantitative rt-PCR in cortical neurons cultured from newborn wild-type or syntaxin-1A knockout (KO) mice. Syntaxin-1A KO neurons were infected at DIV5-7 with a control lentivirus (Control) or with lentiviruses expressing shRNAs to syntaxin-1 without (Synt KD) or with coexpression of shRNA-resistant syntaxin-1A mRNA (KD + Synt1A). Neurons were analysed at DIV13-16, and RNA levels were normalized to those of wild-type neurons (ND = non-detectable). (B) Representative immunoblot (left) and summary quantification (right) of synaxin-1 protein levels in neurons obtained as described in (A). Reactive proteins were visualized by enhanced chemiluminescence (left), but quantified with ${ }^{125}$ I-labelled secondary antibodies and phosphoImager detection (right). (C) Representative images (left) and quantification of synapse density (right) in control, Synt KD, and KD + Synt1A neurons analysed by double immunofluorescence labelling for MAP2 (blue) and synapsin (red). (D) Representative traces (left) and summary graphs of the amplitudes (right) of inhibitory postsynaptic currents (IPSCs) evoked by isolated action potentials in cortical neurons cultured from syntaxin-1A KO mice and infected with control lentivirus (Control), or lentiviruses expressing only syntaxin-1 shRNAs (Synt KD) or syntaxin shRNAs plus either wild-type syntaxin-1A (KD + Synt1A) or wild-type syntaxin-1B (KD + Synt1B). (E) Representative traces (left) and summary graphs of the total synaptic charge transfer (right) of IPSCs evoked by 10 stimuli applied at $10 \mathrm{~Hz}$ in neurons described in (D). Data shown are means \pm SEMs. In (A, B), three independent neuronal cultures were examined; in (C-E), numbers of experiments/neuronal cultures (C) or patched neurons/neuronal cultures (D, E) analysed are shown in the bars; statistical assessments were performed by Student's t-test $\left({ }^{*} P<0.05,{ }^{*} P<0.01\right.$, and ${ }^{* * *} P<0.001$, all versus control). Source data for this figure is available on the online supplementary information page.

\section{The syntaxin-1 N-peptide is essential for fusion}

To test whether the N-peptide of syntaxin-1 is functionally important, we further characterized the impairment in neurotransmitter release produced by the syntaxin-1 deficiency, and examined whether mutant syntaxin-1A lacking the $\mathrm{N}$-peptide can rescue the impairment in neurotransmitter release in syntaxin-1-deficient neurons. As above, neurotransmitter release was measured by monitoring synaptic transmission in cultured neurons using an approach described in detail previously (Maximov and Südhof, 2005; Maximov et al, 2007; Pang et al, 2010; Kaeser et al, 2011).

We initially studied spontaneous release. The syntaxin-1 deficiency severely impaired the frequency of spontaneous release events at both excitatory and inhibitory synapses (monitored as miniature excitatory postsynaptic currents (mEPSCs) and inhibitory postsynaptic currents (mIPSCs), respectively). Wild type-but not $\mathrm{N}$-terminally deleted syntaxin-1A (Synt $1^{\Delta \mathrm{N}}$; Figure $\left.3 \mathrm{~A}\right)$-was able to rescue this 

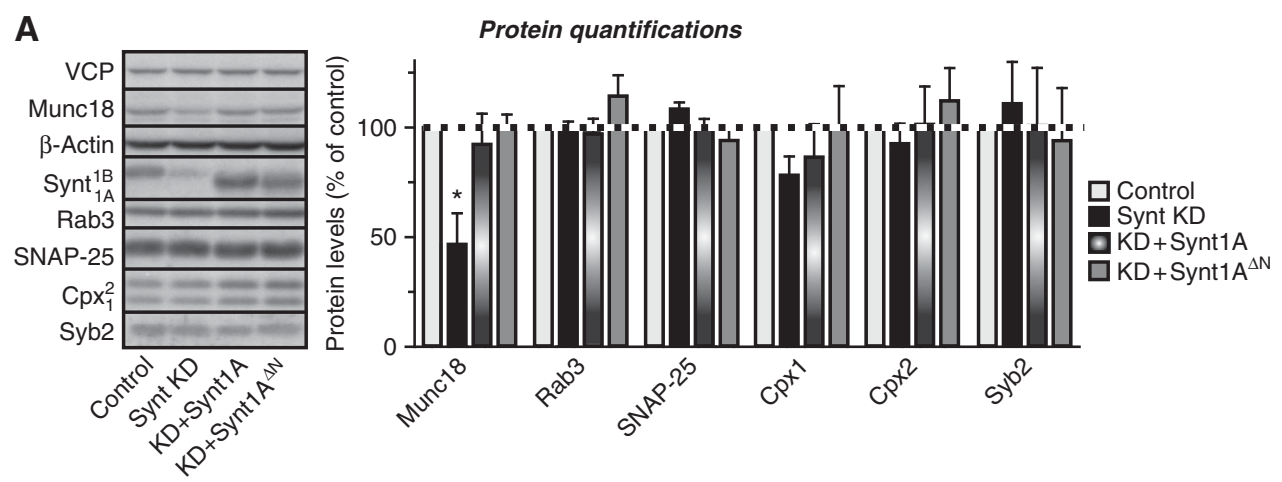

B
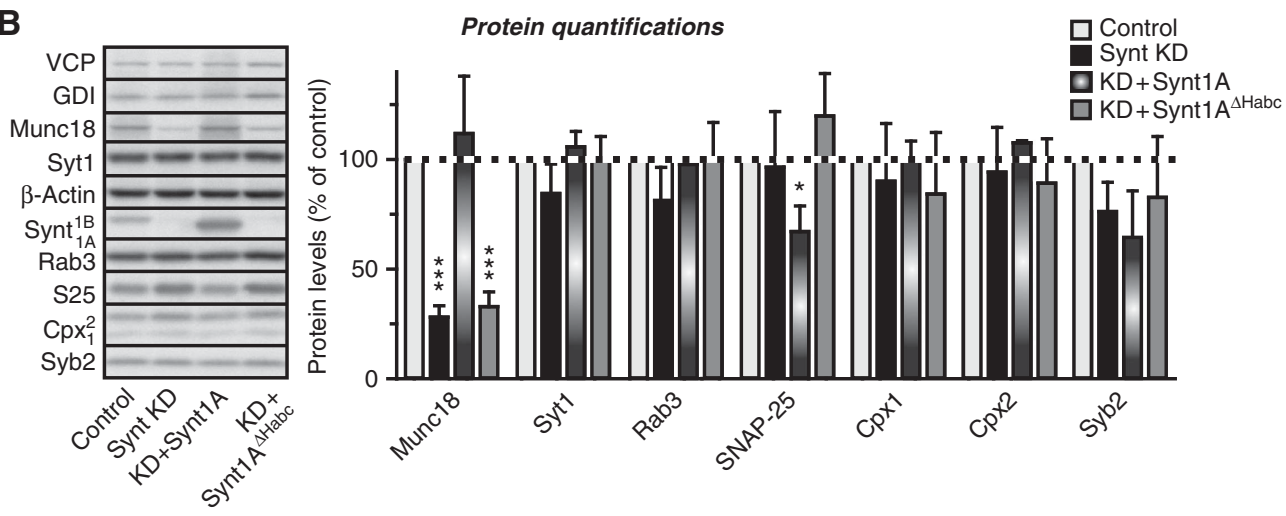

Figure 2 Syntaxin-1 $\mathrm{H}_{\mathrm{abc}}$-domain but not N-peptide is required for maintenance of Munc18-1. (A) Representative immunoblots (left) and quantification of the levels (right) of proteins from cortical neurons cultured from syntaxin-1A KO mice and infected with control lentivirus (Control) or lentiviruses expressing the syntaxin-1 KD alone (Synt1 KD) or together with wild-type syntaxin-1A (KD + Synt1A) or N-terminally truncated syntaxin-1A (KD + Synt $1 \mathrm{~A}^{\Delta \mathrm{N}}$; see Figure 3A). Blots were probed with antibodies to the indicated proteins (VCP, p97/vasolin-containing protein; GDI, guanosine diphosphate dissociation inhibitor; S25, SNAP-25; Cpx, complexin; Syb-2, synaptobrevin-2), and quantified after visualization with ${ }^{125}$ I-labelled secondary antibodies. (B) Same as (A), except that the effect of the $\mathrm{H}_{\mathrm{abc}}$-domain deletion in syntaxin-1A (KD + Synt $1 \mathrm{~A}^{\Delta \mathrm{Habc}}$; see Figure $5 \mathrm{~A}$ ) was analysed. Expression of $\mathrm{H}_{\mathrm{abc}}$-domain deficient syntaxin-1A cannot be visualized because the antibody epitope for syntaxin- 1 is in the $\mathrm{H}_{\mathrm{abc}}$-domain. Data shown are means \pm SEMs ( $n=3$ independent neuronal cultures); statistical assessments were performed by Student's $t$-test $\left({ }^{*} P<0.05,{ }^{* *} P<0.001\right.$, all versus control). Source data for this figure is available on the online supplementary information page.

impairment (Figures 3A-C). No significant changes in mEPSC or mIPSC amplitudes were noted. Moreover, the syntaxin-1 deficiency decreased the size of the RRP of vesicles at inhibitory synapses, monitored as the IPSCs induced by application of hypertonic sucrose (Rosenmund and Stevens, 1996; Figure 3D). Again, wild-type syntaxin-1A nearly completely rescued the phenotype, whereas $\mathrm{N}$-terminally deleted syntaxin-1A did not.

We then went on to measure evoked neurotransmitter release, probed as IPSCs induced by isolated action potentials. Similarly to spontaneous release, the syntaxin-1 deficiency impaired release evoked by isolated action potentials (Figure 4A). Again, this phenotype was rescued by wild-type but not by $\mathrm{N}$-peptide-deficient syntaxin-1A. In addition, the syntaxin-1 deficiency produced a striking change in the kinetics and reliability of evoked IPSCs, suggesting that it delays the speed of neurotransmitter release and desynchronizes release (Figure 4B). The rise times of IPSCs were decreased almost two-fold, and the standard deviation (SD) of the rise times of IPSCs (which serves as a measure of variability between events) was increased $>4$-fold (Figure 4B). This phenotype was also rescued by wild-type but not by N-peptide-deficient syntaxin-1A, consistent with the essential role of the N-peptide in fusion.

Finally, we measured the effect of the syntaxin-1 deficiency on IPSCs induced by a 1-s $10 \mathrm{~Hz}$ stimulus train. We found that the total charge transfer during the train was again severely impaired; this phenotype was also rescued by wild-type but not by N-peptide-deficient syntaxin-1A (Figure 4C; Supplementary Figure S1). The impairment in evoked release during a stimulus train induced by the syntaxin-1 deficiency extended to delayed release, and we observed no syntaxin-1dependent change in the ratio of delayed release to total release induced by the stimulus train (Figure 4D). Together, these findings demonstrate that the Munc18-1 binding site of the syntaxin-1 N-peptide is essential for synaptic membrane fusion, confirming and extending previous conclusions that binding of Munc18-1 to the N-terminal sequence of syntaxin-1 plays a crucial role in membrane fusion (Khvotchev et al, 2007; Shen et al, 2007, 2010; Tareste et al, 2008; Deák et al, 2009; Rathore et al, 2010; however, see Meijers et al, 2012 for an opposing view).

\section{The $N$-peptide remains functionally essential in constitutively open syntaxin-1}

At least three hypotheses could account for the essential role of the Munc18-binding N-peptide of syntaxin-1 in fusion. The $\mathrm{N}$-peptide may be involved in stabilizing Munc18-1 levels, it may be required because Munc18-1 binding to syntaxin enables a direct function of Munc18-1 in membrane fusion, or because Munc18-1 opens the closed conformation of syntaxin-1 (to which Munc18-1 also binds, independent of 
the N-peptide; Hata et al, 1993; Dulubova et al, 1999), which controls the speed of SNARE-complex assembly (Gerber et al, 2008). The data in Figure $2 \mathrm{~A}$ already rule out the first hypothesis. To differentiate between the two remaining hypotheses, we tested whether the functional requirement for the N-peptide of syntaxin-1 was abolished by constitutively opening the closed conformation of syntaxin-1. To open syntaxin-1, we used the 'LE mutation' that shifts the default 'closed' conformation of syntaxin-1A into a preferentially 'open' state (Dulubova et al, 1999; Figure 5A).

We found that LE-mutant syntaxin-1A was fully active in fusion, consistent with previous results (Gerber et al, 2008). However, deletion of the N-peptide from syntaxin-1 impaired

\section{A}

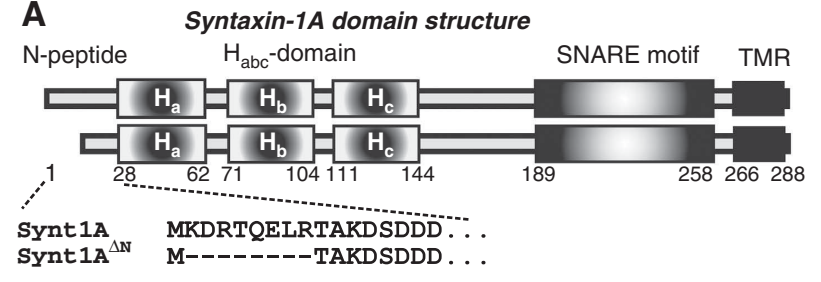

B
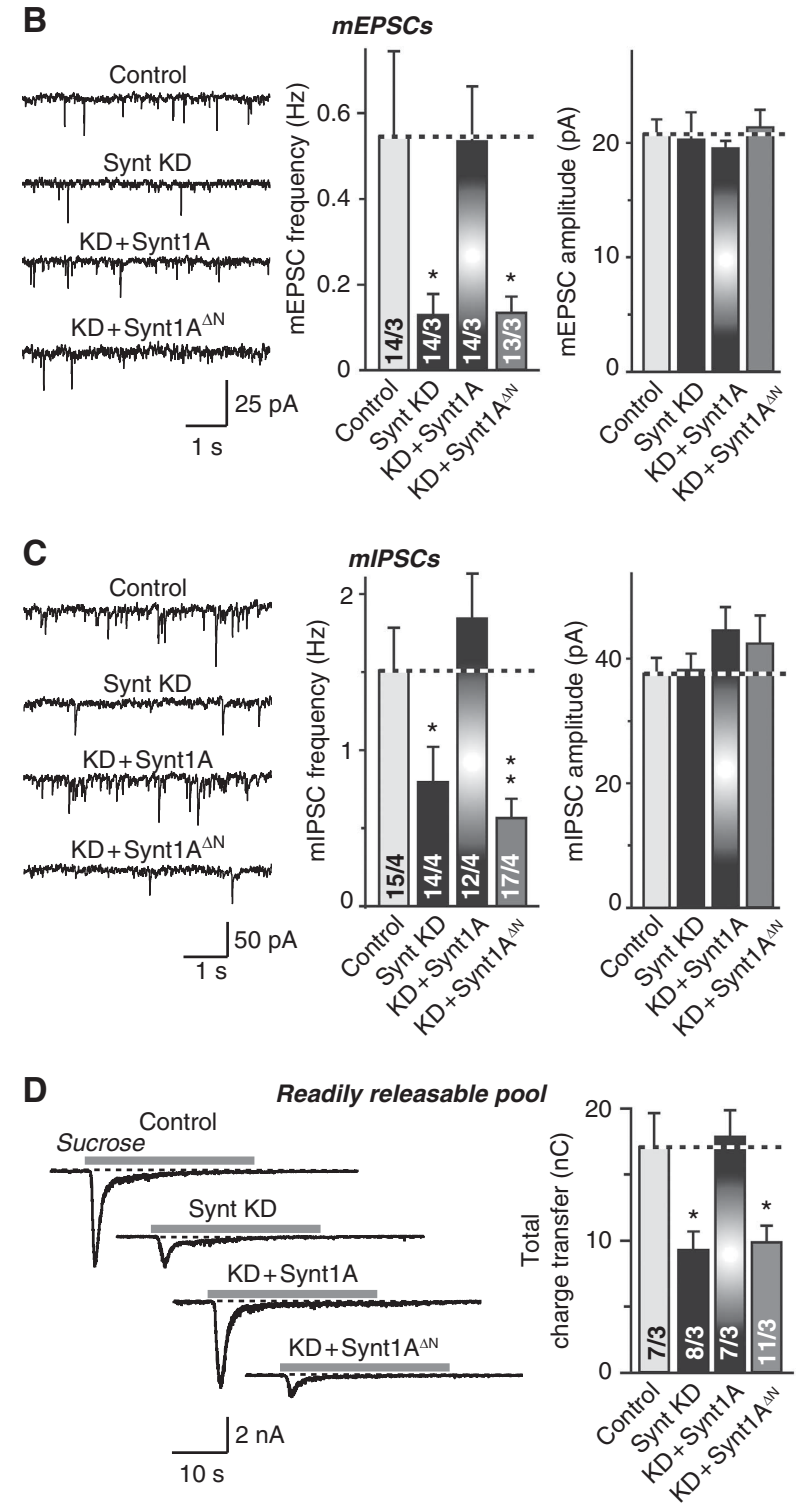

fusion even when the LE mutation was present and when syntaxin-1 was constitutively open (Figures 5A and B). Thus, opening syntaxin-1 does not render the N-peptide non-essential, and Munc18-1 likely does not simply function to 'open' syntaxin-1 during fusion in vivo. However, the LE mutation did rescue the slow, desynchronized kinetics of release in syntaxin-deficient synapses expressing N-peptide deleted syntaxin-1A (Figure 5C), probably because it itself accelerates SNARE-complex assembly and fusion.

To further validate the conclusion that the N-peptide of synaxin-1 is essential for synaptic membrane fusion, we also examined EPSCs evoked by isolated action potentials. We found that the syntaxin-1 deficiency dramatically decreased the amplitude of evoked EPSCs similar to IPSCs, and that this phenotype was also rescued by wild-type syntaxin-1A or by LE-mutant syntaxin-1A (Figure 5D). However, deletion of the $\mathrm{N}$-peptide from either wild-type or LE-mutant syntaxin-1A again blocked its ability to rescue the syntaxin-1 deficiency phenotype, documenting the general requirement for the $\mathrm{N}$-peptide in synaptic membrane fusion.

\section{The syntaxin-1 $\mathrm{H}_{a b c}$-domain performs multiple functions in synaptic vesicle fusion}

We next analysed the in vivo role of the $\mathrm{H}_{\mathrm{abc}}$-domain of syntaxin-1 in fusion to resolve the puzzling observation that despite its evolutionary conservation and size, the $\mathrm{H}_{\mathrm{abc}}$-domain is dispensable for fusion in vitro (Rathore et al, 2010; Shen et al, 2010). However, in rescue experiments with syntaxin-1-deficient neurons, we found that syntaxin-1 lacking the $\mathrm{H}_{\mathrm{abc}}$-domain but still containing the $\mathrm{N}$-peptide (Figure 6A) was unable to rescue the decrease in spontaneous release that is induced by the syntaxin-1 deficiency (Figures 6B and C). Moreover, syntaxin-1A lacking the $\mathrm{H}_{\mathrm{abc}}$-domain did not rescue the decrease in the RRP in syntaxin-deficient neurons (Figure 6D), consistent with the inability of synaxin-1A lacking the $\mathrm{H}_{\mathrm{abc}}$-domain to reverse the decrease in Munc18-1 levels in synaxin-1-deficient neurons (Figure 2B). Since vesicle priming depends on Munc18-1 (Gulyás-Kovács et al, 2007; Deak et al, 2009), the loss of Munc18-1 could account for the decrease in the RRP observed with mutant syntaxin-1 lacking the $\mathrm{H}_{\mathrm{abc}}$-domain, but it does not explain the decrease in spontaneous mini release (see Discussion).

Figure 3 Syntaxin-1 N-peptide is essential for spontaneous synaptic vesicle fusion and for maintenance of the readily releasable pool (RRP) of vesicles. (A) Domain structures and N-terminal sequences of wild-type (top; Synt1A) and mutant syntaxin-1A with a deletion of the N-peptide (bottom; Synt1 $\mathrm{A}^{\Delta \mathrm{N}}$ ). (B, C) Representative traces (left) and summary graphs of the frequency (middle) and amplitudes (right) of miniature excitatory (mEPSCs; B) and miniature inhibitory postsynaptic currents (mIPSCs; C) in cortical neurons cultured from syntaxin-1A KO mice and infected with control lentivirus (Control), or lentiviruses expressing only syntaxin-1 shRNAs (Synt KD) or syntaxin shRNAs plus either wild-type syntaxin-1A (KD + Synt1A) or $\mathrm{N}$-terminally truncated syntaxin-1A $\left(\mathrm{KD}+\right.$ Synt1A $\left.^{\Delta \mathrm{N}}\right)$. (D) Representative traces (left) and summary graphs of the total synaptic charge transfer (right) of IPSCs evoked by a 30-s application of $0.5 \mathrm{M}$ hypertonic sucrose to induce exocytosis of the RRP of vesicles, monitored in cortical neurons as described for (B). Data shown in summary graphs are means \pm SEMs; numbers of cells/independent cultures analysed are listed in the bars. Statistical assessments were performed by Student's $t$-test comparing a test condition to the control $\left({ }^{*} P<0.05 ;{ }^{*} P<0.01\right)$. 
A

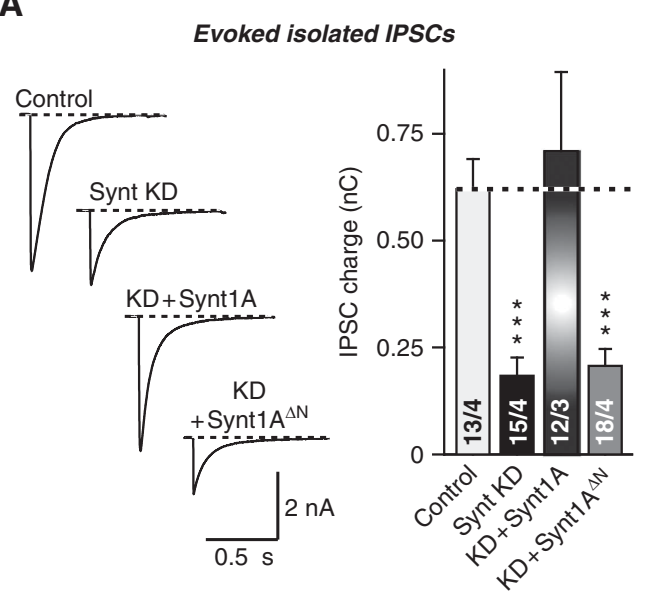

C

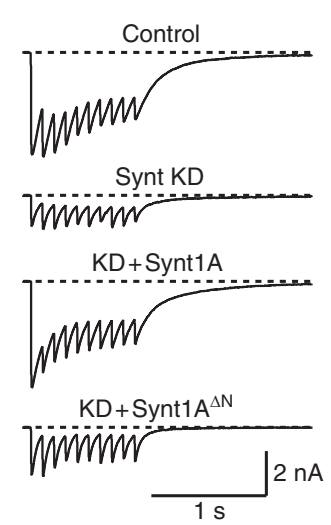

B

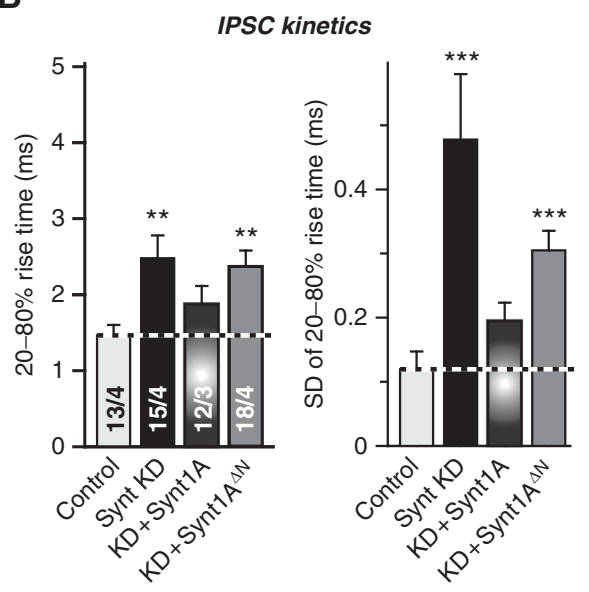

D

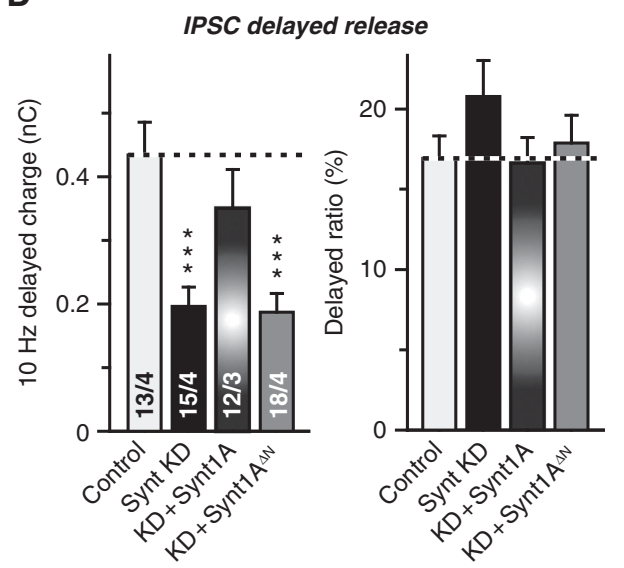

Figure 4 Syntaxin-1 N-terminal peptide is essential for evoked synaptic vesicle fusion. (A) Representative traces (left) and summary graphs of the charge transfer (right) of inhibitory postsynaptic currents (IPSCs) evoked by isolated action potentials in cortical neurons obtained as described for Figure 2B. (B) Summary graphs of the IPSC rise times (left) and the variability of IPSC rise times (expressed as the standard deviation of rise times; right). (C) Representative traces (left) and summary graphs of the total synaptic charge transfer (right) of IPSCs evoked by 10 stimuli applied at $10 \mathrm{~Hz}$. (D) Summary graphs of delayed release (left) and the ratio of delayed to total release (right) measured in the experiments described in (C). Delayed release is defined as the synaptic charge transfer occurring $100 \mathrm{~ms}$ after the last train stimulus (Maximov and Südhof, 2005). Data shown are means \pm SEMs; numbers of cells/independent cultures analysed are shown in the bars. Statistical assessments were performed by Student's $t$-test comparing a condition to the control $(* * P<0.01$; $* * * P<0.001)$.

Surprisingly but fully consistent with the in vitro fusion data, $\mathrm{H}_{\mathrm{abc}}$-domain deleted syntaxin-1A was able to reverse the decrease in the size of evoked EPSCs and IPSCs induced by the syntaxin-1 deficiency (Figures 7A and B). Moreover, $\mathrm{H}_{\mathrm{abc}}$ domain deleted syntaxin-1A rescued the deceleration and desynchronization of release in syntaxin-1-deficient synapses (Figure 7C). Furthermore, when we probed the effect of the $\mathrm{H}_{\mathrm{abc}}$-domain deletion on release induced by a $10-\mathrm{Hz}$ stimulus train (Figures 7D and E), we again observed that the $\mathrm{H}_{\mathrm{abc}}{ }^{-}$ domain deleted syntaxin-1A fully rescued the impairment in release, although it did lead to increase short-term synaptic depression and a change in paired-pulse depression (Supplementary Figures S1 and S2). Thus, deletion of the $\mathrm{H}_{\mathrm{abc}}$-domain of syntaxin-1A does not impair action potentialevoked release, but blocks the ability of syntaxin-1A to rescue the loss of spontaneous release and the decrease in the RRP. We also tested whether the $\mathrm{N}$-peptide was still required for the ability of $\mathrm{H}_{\mathrm{abc}}$-domain deleted syntaxin-1 to support evoked neurotransmitter release, as it is for wild-type syntaxin-1 and for LE-mutant syntaxin-1. Strikingly, we found that deletion of the
$\mathrm{N}$-peptide in addition to the $\mathrm{H}_{\mathrm{abc}}$-domain blocked its ability to rescue release (Supplementary Figure S3). This finding provides further evidence for the hypothesis that the Munc18-binding $\mathrm{N}$-peptide of syntaxin-1 is invariably required for the function of syntaxin-1 in membrane fusion. Together, these findings support the overall notion that syntaxin- 1 always acts in a complex with Munc18-1 in fusion, and confirm previous results showing that the $\mathrm{H}_{\mathrm{abc}}$-domain is not essential for syntaxin- 1 function in fusion as such (Rathore et al, 2010; Shen et al, 2010).

Finally, we examined a syntaxin-1A mutant that contained-in addition to the $\mathrm{H}_{\mathrm{abc}}$-domain deletionasparagine substitutions in a conserved string of five aspartate residues at the N-terminus of syntaxin-1A (Figure 6A). The asparagine substitution mutant was examined to test the possibility that the aspartate residues might function as a $\mathrm{Ca}^{2+}$-binding site that controls asynchronous release (Sun et al, 2007). It was tested in the context of the $\mathrm{H}_{\mathrm{abc}}$-domain deletion because expression of the same substitution mutant on the background of wild-type syntaxin-1A appeared to cause lower expression levels. The asparagine substitutions 


\section{Syntaxin-1A domain structure}

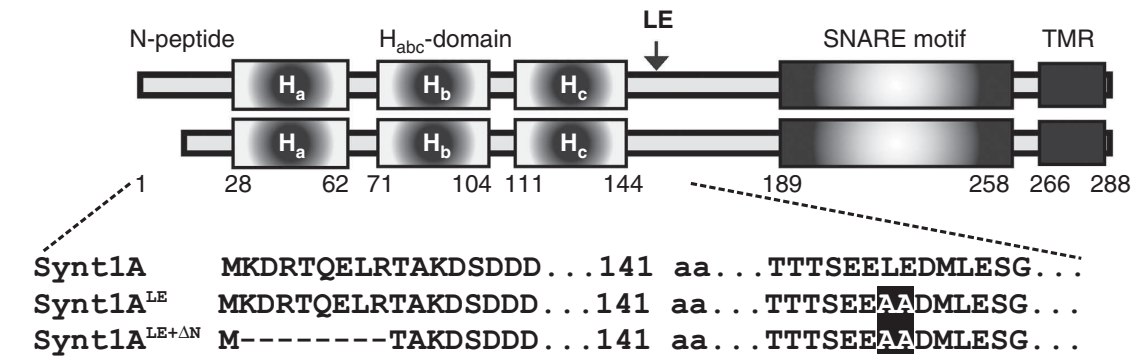

B

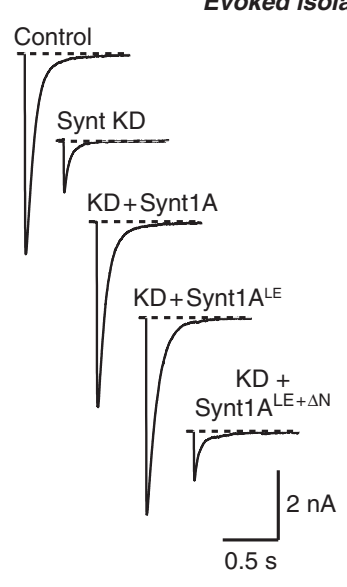

ated IPSCS

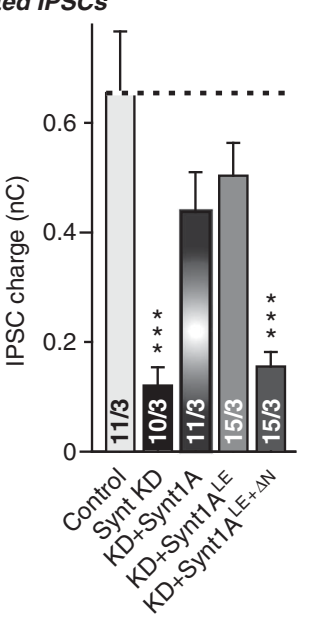

C

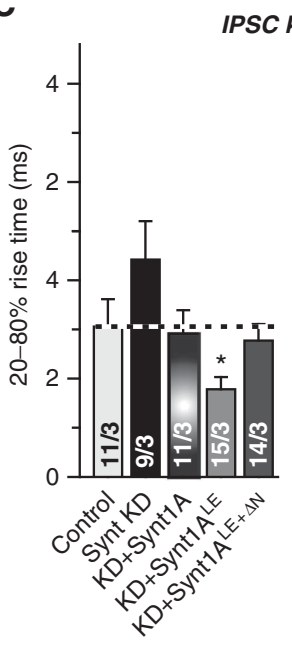

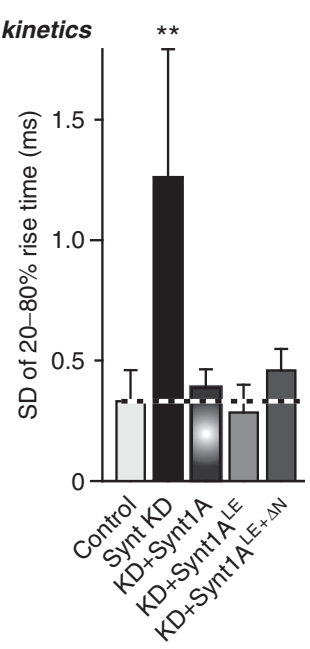

D
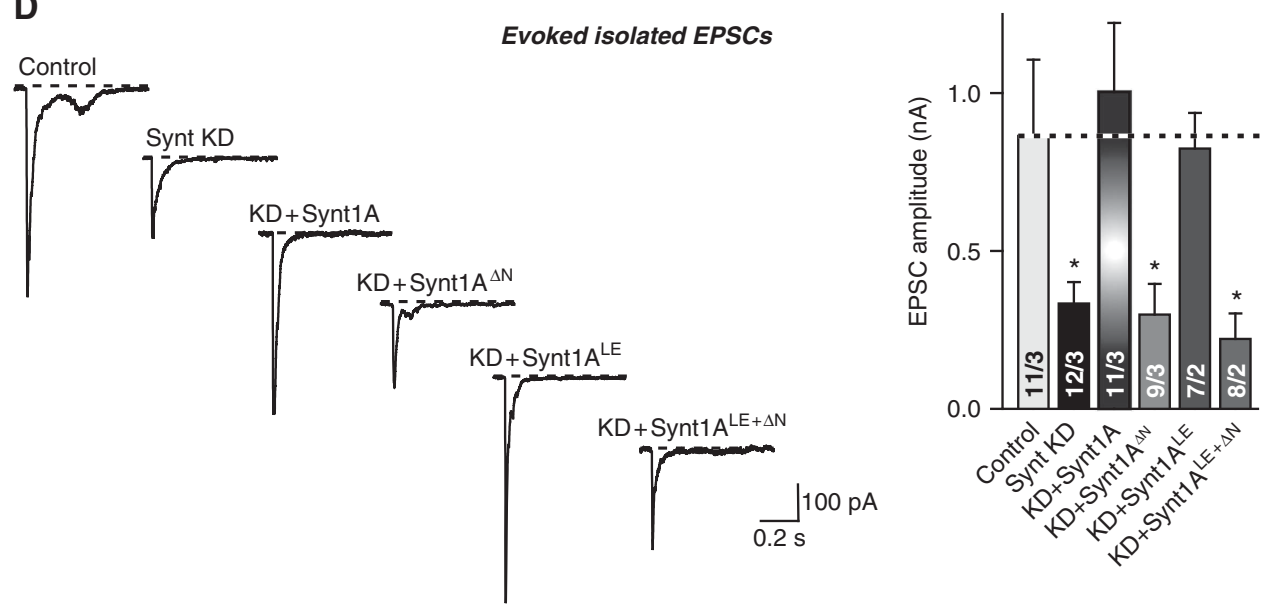

Figure 5 Opening up syntaxin-1 rescues the impaired kinetics but not the decreased magnitude of IPSCs induced in the presence of syntaxin$1 \mathrm{~A}$ lacking the N-peptide. (A) Domain structures and N-terminal sequences of wild-type (top; Synt1A) and mutant syntaxin-1A with the LE mutation that renders syntaxin-1 constitutively open (Dulubova et al, 1999) without (Synt1 $\mathrm{A}^{\mathrm{LE}}$ ) and with an additional deletion of the $\mathrm{N}$-peptide $\left(\right.$ Synt $1 \mathrm{~A}^{\mathrm{LE}+\Delta \mathrm{N}}$ ). (B) Representative traces (left) and summary graphs of the synaptic charge transfer (right) of IPSCs evoked by isolated action potentials in cortical neurons cultured from syntaxin-1A KO mice and infected with control lentivirus (Control) or lentivirus expressing only syntaxin-1 shRNAs (Synt KD), or syntaxin-1 shRNAs plus either wild-type syntaxin-1A (KD + Synt1A), LE mutant constitutively open syntaxin-1A (KD+Synt1 $\mathrm{A}^{\mathrm{LE}}$; see Dulubova et al, 1999), or N-terminally truncated, LE-mutant syntaxin-1A

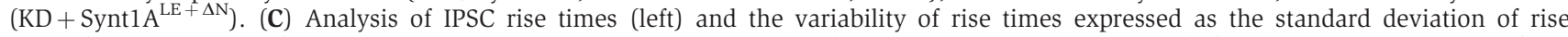
times (right). Data are from the same experiments as those shown in (A). (D) Representative traces (left) and summary graphs of the amplitudes (right) of EPSCs evoked by isolated action potentials in cortical syntaxin-1A KO neurons infected with control lentivirus (Control) or lentivirus expressing only syntaxin-1 shRNAs (Synt KD), or syntaxin-1 shRNAs plus either wild-type syntaxin-1A (KD + Synt1A),

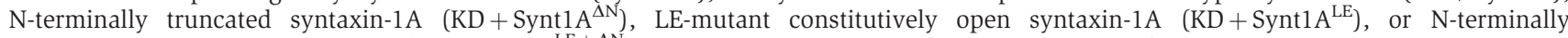
truncated, LE-mutant syntaxin-1A $\left(\mathrm{KD}+\mathrm{Synt} 1 \mathrm{~A}^{\mathrm{LE}+\Delta \mathrm{N}}\right)$. Data shown are means $\pm \mathrm{SEMs}$; numbers of cells/independent cultures analysed are shown in the bars. Statistical assessments were performed by Student's $t$-test comparing a condition to the control $\left({ }^{*} P<0.05\right.$; ${ }^{*} P<0.01$; $* * * P<0.001)$.

had no effect on the ability of $\mathrm{H}_{\mathrm{abc}}$-domain deleted syntaxin$1 \mathrm{~A}$ to rescue evoked release in syntaxin-1-deficient synapses, or its inability to rescue spontaneous release or the RRP
(Figures 6 and 7). This result indicates that the poly-aspartate sequence is unlikely to represent a $\mathrm{Ca}^{2+}$-sensor motif of major physiological significance. 


\section{Discussion}

In the present study, we used a molecular replacement approach to examine the function of the $\mathrm{N}$-terminal domains of syntaxin-1. We knocked down syntaxin-1B in syntaxin-1A KO neurons, and replaced the eliminated syntaxin-1 with wildtype and mutant forms of syntaxin-1A. The N-terminal sequences of syntaxin-1 include two identifiable domains: the short $\mathrm{N}$-peptide and the longer $\mathrm{H}_{\mathrm{abc}}$-domain (Fernandez et al, 1998; Dulubova et al, 2007; Shen et al, 2007, 2010). Interestingly, both N-terminal domains bind to Munc18-1, but by independent mechanisms. The N-peptide binds directly to Munc18-1 similar to the binding of the N-peptide of other syntaxins to their cognate SM proteins (Yamaguchi et al, 2002; Dulubova et al, 2003, 2007; Khvotchev et al, 2007; Shen et al, 2007, 2010), whereas the $\mathrm{H}_{\mathrm{abc}}$-domain binds independent of the $\mathrm{N}$-peptide when the $\mathrm{H}_{\mathrm{abc}}$-domain is folded back onto the SNARE motif in the closed conformation of syntaxin-1 (Dulubova et al, 1999; Misura et al, 2000).

Our experiments allow three major conclusions. First, the $\mathrm{N}$-peptide is essential for syntaxin-1 function in fusion as such; second, the Munc18-1 binding site of the $\mathrm{H}_{\mathrm{abc}}$-domain but not the Munc18-1 binding site of the N-peptide is required for chaperoning Munc18-1 and maintaining its normal levels; and third, the $\mathrm{H}_{\mathrm{abc}}$-domain specifically regulates spontaneous vesicle fusion without being required for evoked synaptic vesicle exocytosis. In conjunction with previous studies, these conclusions suggest a functional domain map of syntaxin-1 that is shown in Figure 8.

\section{The syntaxin-1 N-peptide}

An essential role for the syntaxin-1 N-peptide interaction with Munc18-1 in synaptic vesicle fusion was previously shown using peptide-mediated disruption of this binding reaction in the calyx of Held synapse (Khvotchev et al, 2007), analysis of syntaxin-1 deletion mutants in liposome fusion assays based on lipid mixing (Shen et al, 2007; Rathore et al, 2010) and in C. elegans (McEwen and Kaplan 2008; Johnson et al, 2009; Rathore et al, 2010), and examination of Munc18-1 mutations that block Munc18-1 binding to the N-peptide (Deák et al, 2009). The present study extends this conclusion by demonstrating that deletion of the syntaxin-1 N-peptide also blocks syntaxin-1 function in synaptic vesicle fusion in cultured mammalian neurons, documenting this conclusion by measurements of a variety of parameters including spontaneous release (Figures 3B and C), the RRP (Figure 3D), and evoked synaptic transmission induced by isolated action potentials and action-potential trains (Figures 4A-D).

One hypothesis to explain the essential role of Munc18-1 in fusion had been that Munc18-1 binding to the N-peptide allows Munc18-1 to 'open' closed syntaxin-1 so that it can subsequently form SNARE complexes (reviewed in Südhof and Rizo, 2011). To test this hypothesis, we examined whether constitutively opening syntaxin-1 by the LE mutation (Dulubova et al, 1999) or by deletion of the entire $\mathrm{H}_{\mathrm{abc}}$-domain renders the $\mathrm{N}$-peptide functionally dispensable (Figures 5A and 6A; Supplementary Figure S3). Strikingly, we find that even constitutively open syntaxin-1 or syntaxin-1 lacking the $\mathrm{H}_{\mathrm{abc}}$-domain requires an $\mathrm{N}$-peptide for activity, although the LE mutation does rescue the impairment in release kinetics induced by the N-peptide deletion (Figure 5; Supplementary Figure S3). Collectively, and in agreement with previous data (Khvotchev et al, 2007; Shen et al, 2007; Rodkey et al, 2008; Deak et al, 2009; Johnson et al, 2009; Diao et al, 2010; Rathore et al, 2010; Schollmeier et al, 2011), our results thus support an instrumental role of the N-peptide of syntaxin-1 in synaptic vesicle fusion in vivo.

Our results with the N-peptide-as well as those of Shen et al (2007), Khvotchev et al, (2007), Rodkey et al (2008), Deak et al, (2009), Johnson et al (2009), Diao et al (2010), Rathore et al (2010), and Schollmeier et al (2011) - led to a different conclusion than those of a recent study, which suggested that mutations in Munc18-1 that block binding to the syntaxin-1 N-peptide do not inactivate Munc18-1 function (Meijers et al, 2012). Our present results were obtained with a different approach from that of Meijers et al (2012), as we tested the function of the syntaxin-1 N-peptide in synaptic release. A possible hypothesis to account for these differences in conclusions might be that the N-peptide of syntaxin-1 binds to fusogenic factors other than Munc18-1, despite the high affinity and specificity of this binding reaction. However, other previous studies used similar approaches to Meijers et al (2012) but arrived at different conclusions. For example, we previously showed that mutations in Munc18-1 that disrupt binding to the SNARE complex do disrupt fusion (Deak et al, 2009). Furthermore, the F115E mutation in Munc18-1 that impairs its binding to the syntaxin-1 N-peptide was reported to fully support synaptic transmission in mouse cortical neurons (Meijers et al, 2012), but was unable to sustain synaptic transmission in C. elegans (Johnson et al, 2009). Thus, an alternative explanation for the present differences in conclusions in our view derives from the fact that all of the mutants used by Meijers et al (2012) still partly bind to syntaxin-1, although with diminished affinity. Since the mutant Munc18-1 molecules were overexpressed in cultured neurons but not in C. elegans, it is plausible that a partial loss-of-function could have been overcome in the experiments by Meijer et al (2012) by increased concentrations of the mutant Munc18-1 protein that still binds to the $\mathrm{N}$-peptide. Thus, we feel that on balance, the evidence for a functional role of the syntaxin-1 N-peptide/ Munc18-1 binding in fusion is compelling.

\section{Syntaxin-1 chaperones Munc18-1 via the $H_{a b c}$-domain Munc18-binding site}

The syntaxin-1 deficiency produces an $\sim 50 \%$ decrease in Munc18-1 levels (Figure 2), similarly to the opening of syntaxin-1 with the LE mutation (Gerber et al, 2008). The decrease in Munc18-1 levels is fully rescued with syntaxin-1 lacking the N-peptide (which does not support fusion, but still forms a closed conformation that binds Munc18-1), demonstrating that the loss of Munc18-1 levels is not secondarily due to a decrease in neurotransmitter release but represents an activity of syntaxin-1 that is independent of its function in neurotransmitter release (Figure 2A). Consistent with the requirement of the syntaxin-1 closed conformation for maintaining Munc18-1 levels (Gerber et al, 2008), syntaxin-1 lacking the $\mathrm{H}_{\mathrm{abc}}$-domain was unable to maintain normal Munc18-1 levels (Figure 2B), even though it still fully supported evoked neurotransmitter release (Figure 7). These results indicate that upstream of the common function of Munc18-1 and syntaxin-1 in membrane fusion, the complex formed by closed syntaxin-1 with Munc18-1 (Hata et al, 1993) serves to chaperone both 
A

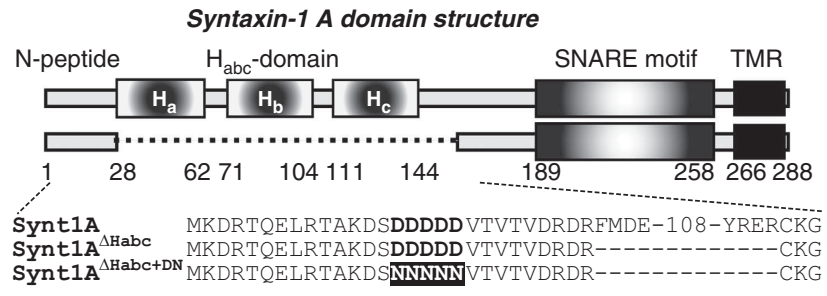

B

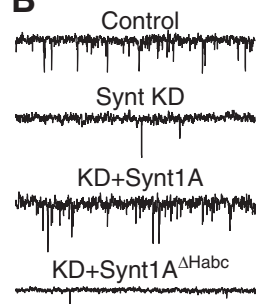

$\prod_{1 \mathrm{~s}} 25 \mathrm{pA}$

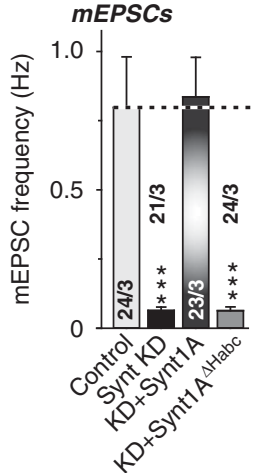

D

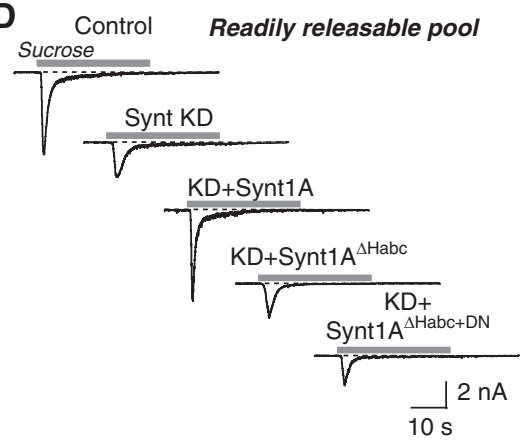

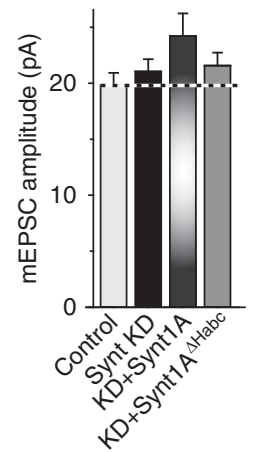

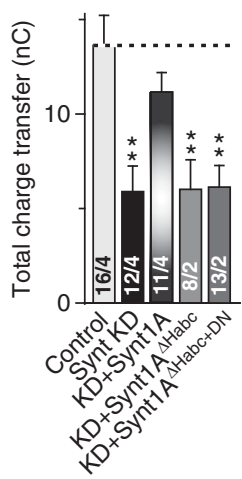

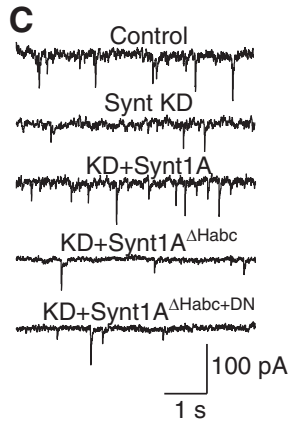

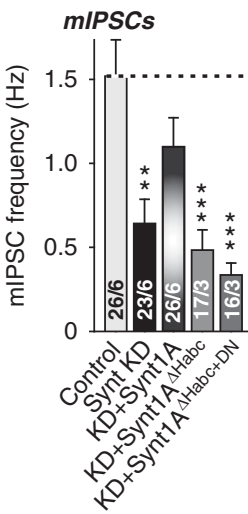

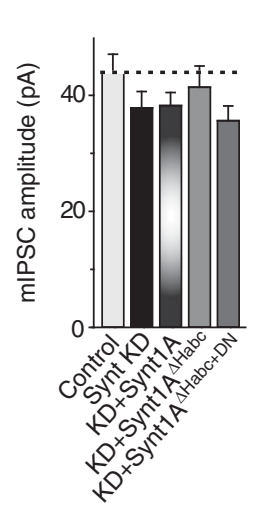

Figure 6 Syntaxin- $1 \mathrm{H}_{\mathrm{abc}}$-domain is essential for spontaneous synaptic vesicle fusion and for maintenance of the RRP. (A) Domain structures of wild-type (top) and $\mathrm{H}_{a b c}$-domain deleted syntaxin-1A (bottom; Synt $1 \mathrm{~A}^{\Delta \mathrm{Habc}}$ ). The sequence alignment below the diagram depicts the $\mathrm{N}$-terminal sequences of wild-type syntaxin-1 $\mathrm{A}, \mathrm{H}_{\mathrm{abc}}$-domain deleted syntaxin- $1 \mathrm{~A}$, and $\mathrm{H}_{\mathrm{abc}}$-domain deleted syntaxin-1A which contained additional asparagine substitutions in the putative $\mathrm{Ca}^{2+}$-binding sequence of syntaxin-1A (the poly-aspartate region; Synt $1 \mathrm{~A}^{\Delta \mathrm{Habc}+\mathrm{DN}}$ ). $(\mathbf{B}, \mathbf{C})$ Representative traces (left) and summary graphs of the frequency (middle) and amplitudes (right) of mEPSCs (B) and mIPSCs (C) in cortical neurons cultured from syntaxin-1A KO mice and infected with control lentivirus (Control) or lentivirus expressing only syntaxin-1 shRNAs

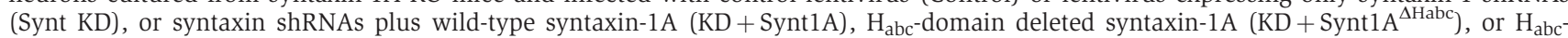
domain deleted syntaxin-1A with an additional substitution of the poly-aspartate residues for poly-asparagine residues $\left(\mathrm{KD}+\right.$ Synt1 $\left.\mathrm{A}^{\Delta \mathrm{Habc}+\mathrm{DN}}\right)$. (D) Representative traces (left) and summary graphs of the total synaptic charge transfer (right) of IPSCs evoked by a 30-s application of $0.5 \mathrm{M}$ hypertonic sucrose to induce exocytosis of the RRP, monitored in cortical neurons as described for (B). Data shown are means \pm SEMs; numbers of cells/independent cultures analysed are shown in the bars. Statistical assessments were performed by Student's $t$-test comparing a condition to the control $\left({ }^{*} P<0.01 ;{ }^{* *} P<0.001\right)$.

molecules, as also suggested by the finding that a loss of one of the two molecules or of the closed conformation of syntaxin-1 results in a decrease in the levels of the other (Verhage et al, 2000; Gerber et al, 2008; Figure 2). Thus, Munc18-1 is not simply a syntaxin-1 chaperone, nor does syntaxin-1 serve only as a Munc18-1 chaperone.

\section{The syntaxin-1 $\mathrm{H}_{a b c}$-domain}

Both the $\mathrm{H}_{\mathrm{abc}}$-domain deletion and the $\mathrm{LE}$ mutation of syntaxin-1 generate an 'open' syntaxin-1 conformation, produce a loss of Munc18-1, and result in a decrease in the RRP, with these three events likely acting as a cause-effect series (Gerber et al, 2008). However, the two syntaxin-1 mutations differ in one major phenotype: the $\mathrm{H}_{\mathrm{abc}}$-domain deletion causes a DECREASE in spontaneous release, whereas the LE mutation results in an INCREASE in spontaneous release (Figure 6). The decrease in spontaneous release produced by the $\mathrm{H}_{\mathrm{abc}}$-domain deletion of syntaxin-1 cannot be explained by the decrease in the RRP because the LE mutation causes the same decrease in the RRP but results in an increase in spontaneous release (Gerber et al, 2008). Thus, our data suggest that the $\mathrm{H}_{\mathrm{abc}}$-domain of syntaxin-1 performs at least one additional function in synaptic vesicle fusion besides chaperoning Munc18-1 and maintaining the RRP: It is essential for spontaneous miniature release (Figure 8).

Why is spontaneous release decreased upon deletion of the $\mathrm{H}_{\mathrm{abc}}$-domain of syntaxin-1, and why is evoked release retained despite the decrease in spontaneous release and in the RRP? As regards the first question, accumulating evidence suggests that spontaneous and evoked release are mechanistically distinct and differentially regulated in central synapses (Sara et al, 2005; reviewed in Sutton and Schuman, 2009 and Ramirez and Kavalali, 2011). Our results suggests that the $\mathrm{H}_{\mathrm{abc}}$-domain may be involved in the differential regulation of spontaneous and evoked release, in addition to mediating the closed conformation of syntaxin-1, although the molecular mechanism by which the $\mathrm{H}_{\mathrm{abc}}$-domain mediates this differential regulation remains unknown. As regards the second question, it seems likely that the loss of the closed conformation in syntaxin-1 lacking an $\mathrm{H}_{\mathrm{abc}}$-domain accelerates and enhances fusion, similar to what was previously shown for LE-mutant syntaxin-1B (Gerber et al, 2008). Thus, a decrease in the RRP is compensated by an increased refilling rate of the RRP and an increased fusion speed. An important general implication of our findings is that spontaneous release cannot be simply considered as a 
A

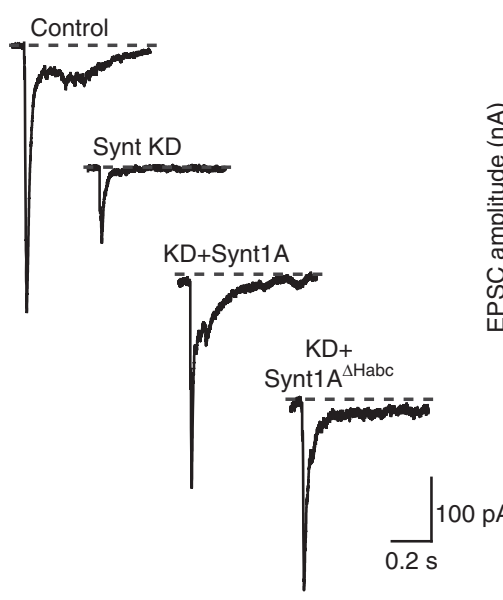

B

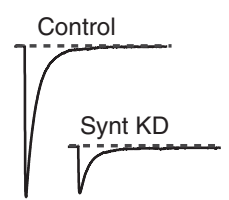

KD+Synt1A

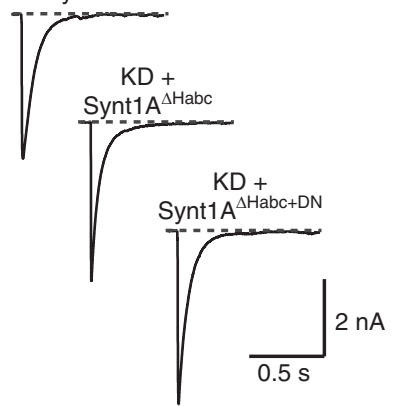

D

$10 \mathrm{~Hz}$ trains of evoked IPSCs

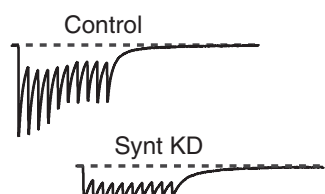

MUMWW
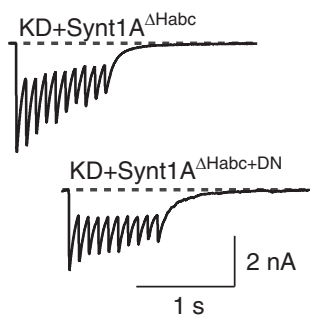

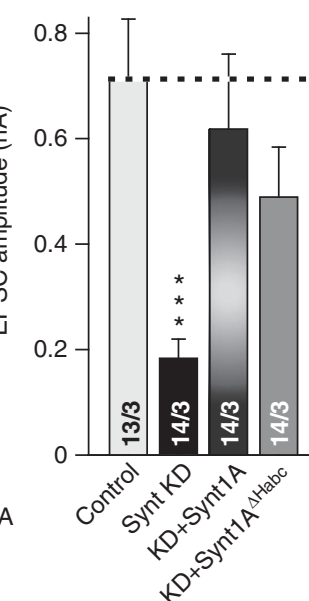

Evoked isolated IPSCs

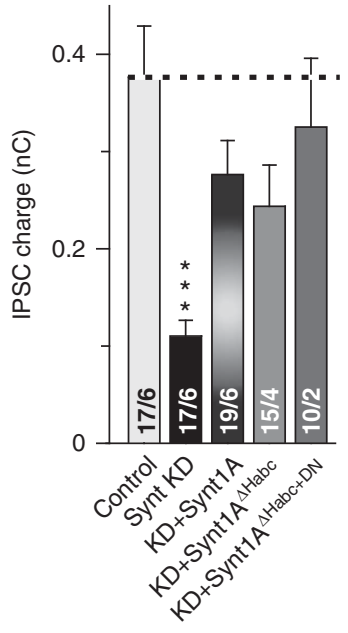

C
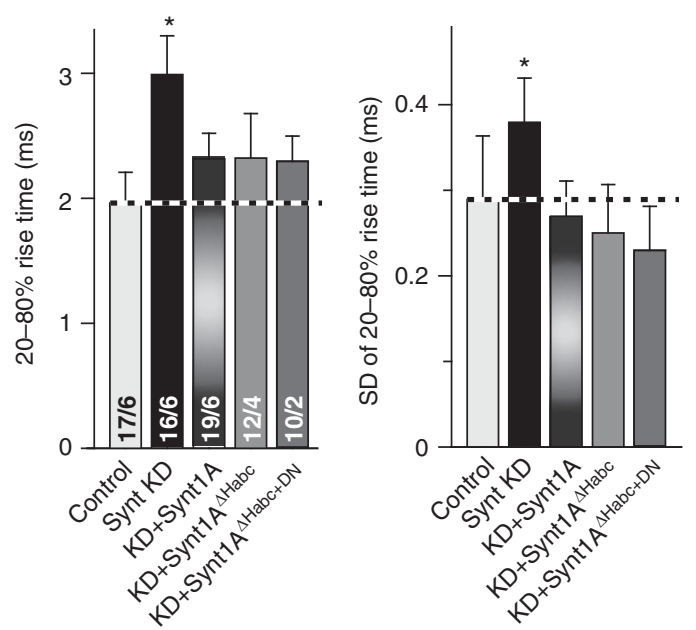

E
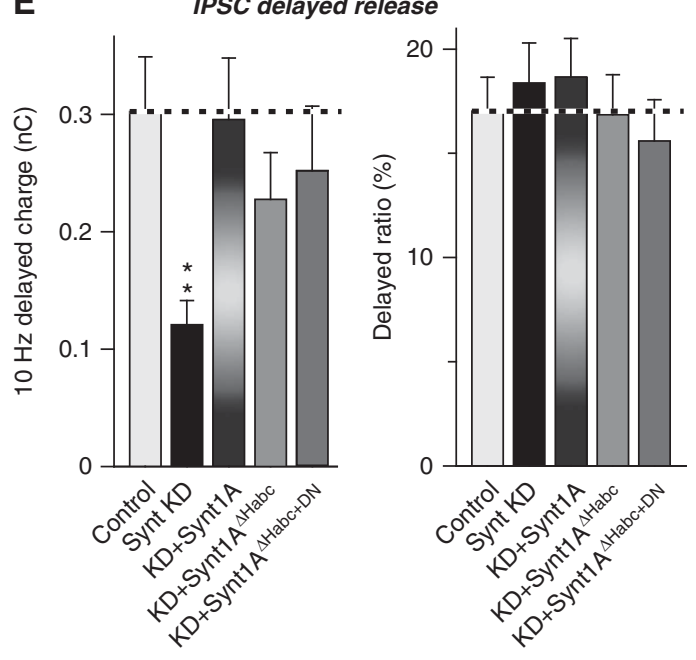

Figure 7 Syntaxin-1 $\mathrm{H}_{\mathrm{abc}}$-domain is not essential for evoked synaptic vesicle fusion. (A) Representative traces (left) and summary graphs of the amplitude (right) of EPSCs evoked by isolated action potentials in cortical neurons obtained as described for Figure 5B. (B) Representative traces (left) and summary graph of the synaptic charge transfer (right) of IPSCs evoked by isolated action potentials in cortical neurons obtained as described in (A). (C) Analysis of IPSC rise times (left) and the variability of IPSC rise times (expressed as the standard deviation of rise times; right), calculated from the experiments shown in (B). (D) Representative traces (left) and summary graphs of the total synaptic charge transfer (right) of IPSCs evoked by 10 stimuli applied at $10 \mathrm{~Hz}$. (E) Summary graphs of delayed release (left) and the ratio of delayed to total release (right) measured in the experiments described in (D). Data shown are means \pm SEMs; numbers of cells/independent cultures analysed are shown in the bars. Statistical assessments were performed by Student's $t$-test comparing a condition to the control $\left({ }^{*} P<0.05\right.$; $\left.{ }^{* *} P<0.01 ;{ }^{* * *} P<0.001\right)$. 


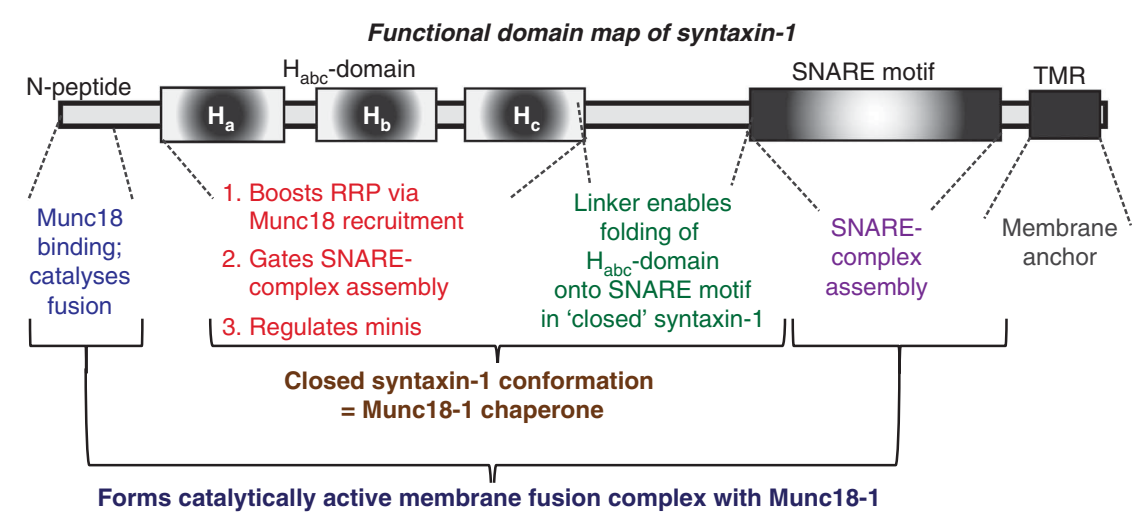

Figure 8 Functional domain structure of syntaxin-1. The attributions of the various functions are based on the present study (for the N-peptide and the $\mathrm{H}_{\mathrm{abc}}$-domain) and previous in vitro and in vivo studies (Dulubova et al, 1999, 2007; Misura et al, 2000; Khvotchev et al, 2007; Shen et al, 2007; Deák et al, 2009; Rathore et al, 2010).

readout of synapse numbers, RRP size, or release probability, but rather represents the combined end result of many processes that include those mentioned above, and additionally involves other processes specific for this mode of release.

In summary, our data indicate that the complex domain structure of syntaxin-1 is required for a multifaceted functional role of syntaxin-1 in different types of synaptic vesicle fusion that includes both evoked and spontaneous fusion (Figure 8). The high degree of conservation among syntaxins, including within their $\mathrm{H}_{\mathrm{abc}}$-domains, indicates that similar functions may also apply to other isoforms in other types of fusion reactions.

\section{Materials and methods}

\section{Neuronal cultures}

Neuronal cultures were obtained from cortex of newborn mice as described (Yang et al, 2010). Neurons were infected with lentiviruses at DIV5-7, and analysed at DIV13-16.

\section{Plasmid construction and production of lentiviruses}

Lentiviral expression vector and three helper plasmids (pRSV-REV, $\mathrm{pMDLg} / \mathrm{pRRE}$ and vesicular stomatitis virus $\mathrm{G}$ protein expression vector) were co-transfected into HEK293T cells (ATCC, VA), at 6, 2, 2 , and $2 \mu \mathrm{g}$ of DNA per $25 \mathrm{~cm}^{2}$ culture area, respectively (Pang et al, 2010), using FuGENE 6 transfection reagent (Roche, UK) or calcium phosphate, and cell-culture supernatants containing the viruses were collected $48 \mathrm{~h}$ after transfection and directly used for infection of neurons. All steps were performed under level II biosafety conditions.

\section{Development and validation of syntaxin-1 shRNAs}

Syntaxin-1A and -1B cDNA sequences were aligned and two conserved regions were chosen as targets of shRNAs (AGAGGCAGCTGGAGATCAC and GATCATCATTTGCTGTGTG). Synthetic shRNA oligonucleotides (sense sequences: TCGACCAGAGG CAGCTGGAGATCACTTCAAGAGA GTGATCTCCAGCTGCCTCTGGTT TTTTGGAAAT and CGCGCCCGATCATCATTTGCT GTGTGT TCAAG AGACACACAGCAAATGATGATCATTTTTTTGGAAA) were inserted into L309 vector (Pang et al, 2010) using XhoI-XbaI and AscI-RsrII sites respectively. The KD effects of the syntaxin-1 shRNAs were validated in wild-type cortical neurons by quantitative RT-PCR.

\section{Immunocytochemistry}

Neurons were fixed and permeabilized at $-20^{\circ} \mathrm{C}$ in $100 \%$ methanol, incubated with anti-MAP2 (mouse monoclonal; Sigma) and antisynapsin (rabbit polyclonal; E028) primary antibodies in PBS with $4 \%$ BSA and $1 \%$ goat serum, washed, and stained with monocolonal anti-MAP2 and polyclonal anti-synapsin and visualized using
Alexa Fluor 633 goat anti-mouse and Alexa Fluor 546 goat antirabbit secondary antibodies (Molecular Probes). Images were acquired by using a Leica TCS2 confocal microscope equipped with $\times 63$ oil-immersion objective with numerical aperture of 1.32 . Identical settings were applied to all samples in each experiment. Stacks of z-section images were acquired and converted to maximal projection images by using Leica Confocal Software, and analysed blindly with a custom Matlab program as described (Nam and Chen, 2005). Images were thresholded by intensity to exclude the diffuse/intracellular pool, and then puncta were quantified by counting the number of supra-threshold areas of sizes between 0.25 and $4 \mu \mathrm{m}^{2}$. Representative images were merged using Image J $1.44 \mathrm{p}$ software. Presynaptic terminals (visualized via synapsin staining) were presented in red, and dendrites (MAP2 staining) in blue.

\section{Protein quantifications}

Proteins from cultured neurons harvested in cold SDS sample buffer at DIV14-16 were resolved by $10-12 \%$ SDS-PAGE, transferred onto nitrocellulose membranes, and reacted with antibodies to syntaxin1 (polyclonal; 438B), Munc18 (monoclonal; BD Biosciences), Syt1 (monoclonal; CL41.1), Rab3 (polyclonal; T957), SNAP-25 (polyclonal; P913), complexins (polyclonal; L668 and L669), synaptobrevin2 (polyclonal; P939), VCP (polyclonal; 433B), and GDI (monoclonal; Synaptic Systems). Signals were quantified using ${ }^{125}$ I-labelled secondary antibodies and Phosphorimager detection.

\section{Electrophysiological recordings}

Electrophysiological recordings were performed in whole-cell patchclamp mode using concentric extracellular stimulation electrodes (Yang et al, 2010). Evoked synaptic responses were triggered by a bipolar electrode placed $100-150 \mu \mathrm{m}$ from the soma of neurons recorded. Patch pipettes were pulled from borosilicate glass capillary tubes (Warner Instruments) using a PC-10 pipette puller (Narishige). The resistance of pipettes filled with intracellular solution varied between 3 and $5 \mathrm{MOhm}$. After formation of the whole-cell configuration and equilibration of the intracellular pipette solution, the series resistance was adjusted to $8-10 \mathrm{MOhm}$. Synaptic currents were monitored with a Multiclamp 700B amplifier (Molecular Devices). The frequency, duration, and magnitude of the extracellular stimulus were controlled with a Model 2100 Isolated Pulse Stimulator (A-M Systems, Inc.) synchronized with Clampex 10 data acquisition software (Molecular devices). The whole-cell pipette solution contained (in mM) $120 \mathrm{CsCl}, 10$ HEPES, 10 EGTA, 0.3 Na-GTP, 3 Mg-ATP and 5 QX-314 (pH 7.2, adjusted with $\mathrm{CsOH}$ ). The bath solution contained (in $\mathrm{mM}$ ) $140 \mathrm{NaCl}, 5 \mathrm{KCl}, 2 \mathrm{MgCl}_{2}, 2 \mathrm{CaCl}_{2}$, 10 HEPES-NaOH, and 10 glucose (pH 7.4). IPSCs and EPSCs were pharmacologically isolated by adding the AMPA and NMDA receptor blockers CNQX $(20 \mu \mathrm{M})$ and AP-5 $(50 \mu \mathrm{M})$ or the $\mathrm{GABA}_{\mathrm{A}^{-}}$ receptor blockers picrotoxin $(50 \mu \mathrm{M})$ to the extracellular solution. Spontaneous mIPSCs were monitored in the presence of tetrodotoxin (TTX; $1 \mu \mathrm{M}$ ) to block action potentials. Miniature events were analysed in Clampfit 10 (Molecular Devices) using the template matching search and a minimal threshold of $5 \mathrm{pA}$ and each event 
was visually inspected for inclusion or rejection by an experimenter blind to the recording condition. Sucrose-evoked release was triggered by a 30-s application of bath solution to which $0.5 \mathrm{M}$ sucrose were added and which also contained AP-5, CNQX, and TTX.

\section{Statistical analyses}

Statistical analyses were performed with Student's $t$-tests or twoway ANOVA tests comparing test to control samples analysed in the same experiments.

\section{Supplementary data}

Supplementary data are available at The EMBO Journal Online (http://www.embojournal.org).

\section{References}

Antonin W, Dulubova I, Arac D, Pabst S, Plitzner J, Rizo J, Jahn R (2002) The N-terminal domains of syntaxin 7 and vtilb form three-helix bundles that differ in their ability to regulate SNARE complex assembly. J Biol Chem 277: 36449-36456

Bracher A, Weissenhorn W (2004) Crystal structure of the $\mathrm{H}_{\mathrm{abc}}$ domain of neuronal syntaxin from the squid Loligo pealei reveals conformational plasticity at its C-terminus. BMC Struct Biol 4: 6

Deák F, Xu Y, Chang WP, Dulubova I, Khvotchev M, Liu X, Südhof TC, Rizo J (2009) Munc18-1 binding to the neuronal SNARE complex controls synaptic vesicle priming. J Cell Biol 184: 751-764

Diao J, Su Z, Lu X, Yoon TY, Shin YK, Ha T (2010) Single-vesicle fusion assay reveals Munc18-1 binding to the SNARE core is sufficient for stimulating membrane fusion. ACS Chem Neurosci 1: $168-174$

Dulubova I, Yamaguchi T, Araç D, Li H, Huryeva I, Min SW, Rizo J, Südhof TC (2003) Convergence and divergence in the mechanism of SNARE binding by Sec1/Munc18-like proteins. Proc Natl Acad Sci USA 100: $32-37$

Dulubova I, Khvotchev M, Liu S, Huryeva I, Südhof TC, Rizo J (2007) Munc18-1 binds directly to the neuronal SNARE complex. Proc Natl Acad Sci USA 104: 2697-2702

Dulubova I, Sugita S, Hill S, Hosaka M, Fernandez I, Südhof TC, Rizo J (1999) A conformational switch in syntaxin during exocytosis: role of munc18. EMBO J 18: 4372-4382

Fernandez I, Ubach J, Dulubova I, Zhang X, Südhof TC, Rizo J (1998) Three-dimensional structure of an evolutionarily conserved N-terminal domain of syntaxin 1A. Cell 94: 841-849

Gerber SH, Rah JC, Min SW, Liu X, de Wit H, Dulubova I, Meyer AC, Rizo J, Arancillo M, Hammer RE, Verhage M, Rosenmund C, Südhof TC (2008) Conformational switch of syntaxin-1 controls synaptic vesicle fusion. Science 321: 1507-1510

Gulyás-Kovács A, de Wit H, Milosevic I, Kochubey O, Toonen R, Klingauf J, Verhage M, Sørensen JB. (2007) Munc18-1: sequential interactions with the fusion machinery stimulate vesicle docking and priming. J Neurosci 27: 8676-8686

Hata Y, Slaughter CA, Südhof TC (1993) Synaptic vesicle fusion complex contains unc-18 homologue bound to syntaxin. Nature 366: $347-351$

Hu SH, Latham CF, Gee CL, James DE, Martin JL (2007) Structure of the Munc18c/Syntaxin4 N-peptide complex defines universal features of the N-peptide binding mode of Sec1/Munc18 proteins. Proc Natl Acad Sci USA 104: 8773-8778

Johnson JR, Ferdek P, Lian LY, Barclay JW, Burgoyne RD, Morgan A (2009) Binding of UNC-18 to the N-terminus of syntaxin is essential for neurotransmission in Caenorhabditis elegans. Biochem J 418: 73-80

Kaeser PS, Deng L, Wang Y, Dulubova I, Liu X, Rizo J, Südhof TC (2011) RIM proteins tether $\mathrm{Ca}^{2+}$ channels to presynaptic active zones via a direct PDZ-domain interaction. Cell 144: 282-295

Khvotchev M, Dulubova I, Sun J, Dai H, Rizo J, Südhof TC (2007) Dual modes of Munc18-1/SNARE interactions are coupled by functionally critical binding to syntaxin-1N terminus. J Neurosci 27: $12147-12155$

Ko J, Soler-Llavina GJ, Fuccillo MV, Malenka RC, Sudhof TC (2011) Neuroligins/LRRTMs prevent activity- and Ca2 +/calmodulindependent synapse elimination in cultured neurons. J Cell Biol 194: $323-334$

\section{Acknowledgements}

We thank Ira Huryeva for excellent technical support. This study was supported by a Recovery Act grant from the National Institute of Mental Health ([NIMH] 1R01 MH089054), an NIMH Conte Center Award (P50 MH086403), an NARSAD Young Investigator Award (to ZPP), and an NIH NRSA fellowship (1F32NS067896 to TB).

Author contributions: PZ, ZPP, XY, YZ, TB, and TCS designed the experiments, PZ, ZPP, XY, YZ, and TB performed the experiments, and PZ, ZPP, XY, YZ, TB, CR, and TCS wrote the manuscript.

\section{Conflict of interest}

The authors declare that they have no conflict of interest.

Ma C, Li W, Xu Y, Rizo J (2011) Munc13 mediates the transition from the closed syntaxin-Munc18 complex to the SNARE complex. Nat Struct Mol Biol 18: 542-549

Maximov A, Pang ZP, Tervo DG, Südhof TC (2007) Monitoring synaptic transmission in primary neuronal cultures using local extracellular stimulation. J Neurosci Methods 161: 75-87

Maximov A, Südhof TC (2005) Autonomous function of synaptotagmin 1 in triggering synchronous release independent of asynchronous release. Neuron 48: 547-554

McEwen JM, Kaplan JM (2008) UNC-18 promotes both the anterograde trafficking and synaptic function of syntaxin. Mol Biol Cell 19: 3836-3846

Meijer M, Burkhardt P, de Wit H, Toonen RF, Fasshauer D, Verhage M (2012) Munc18-1 mutations that strongly impair SNAREcomplex binding support normal synaptic transmission. EMBO $J$ 31: 2156-2168

Misura KM, Scheller RH, Weis WI (2000) Three-dimensional structure of the neuronal-Sec1-syntaxin 1a complex. Nature 404: 355-362

Nam CI, Chen L (2005) Postsynaptic assembly induced by neurexinneuroligin interaction and neurotransmitter. Proc Natl Acad Sci USA 102: 6137-6142

Pang ZP, Cao P, Xu W, Südhof TC (2010) Calmodulin controls synaptic strength via presynaptic activation of calmodulin kinase II. J Neurosci 30: 4132-4142

Ramirez DM, Kavalali ET (2011) Differential regulation of spontaneous and evoked neurotransmitter release at central synapses. Curr Opin Neurobiol 21: 275-282

Rathore SS, Bend EG, Yu H, Hammarlund M, Jorgensen EM, Shen J (2010) Syntaxin N-terminal peptide motif is an initiation factor for the assembly of the SNARE-Sec1/Munc18 membrane fusion complex. Proc Natl Acad Sci USA 107: 22399-22406

Richmond JE, Weimer RM, Jorgensen EM (2001) An open form of syntaxin bypasses the requirement for UNC-13 in vesicle priming. Nature 412: 338-341

Rickman C, Medine CN, Bergmann A, Duncan RR (2007) Functionally and spatially distinct modes of munc18-syntaxin 1 interaction. J Biol Chem 282: 12097-12103

Rizo J, Rosenmund C (2008) Synaptic vesicle fusion. Nat Struct Mol Biol 15: 665-674

Rodkey TL, Liu S, Barry M, McNew JA (2008) Munc18a scaffolds SNARE assembly to promote membrane fusion. Mol Biol Cell 19: 5422-5434

Rosenmund C, Stevens CF (1996) Definition of the readily releasable pool of vesicles at hippocampal synapses. Neuron 16: 1197-1207

Sara Y, Virmani T, Deak F, Liu X, Kavalali ET (2005) An isolated pool of vesicles recycles at rest and drives spontaneous neurotransmission. Neuron 45: 563-573

Schollmeier Y, Krause JM, Kreye S, Malsam J, Sollner TH (2011) Resolving the function of distinct Munc18-1/SNARE protein interaction modes in a reconstituted membrane fusion assay. $J$ Biol Chem 286: 30582-30590

Shen J, Rathore SS, Khandan L, Rothman JE (2010) SNARE bundle and syntaxin N-peptide constitute a minimal complement for Munc18-1 activation of membrane fusion. J Cell Biol 190: 55-63

Shen J, Tareste DC, Paumet F, Rothman JE, Melia TJ (2007) Selective activation of cognate SNAREpins by Sec1/Munc18 proteins. Cell 128: $183-195$ 
Shi L, Kümmel D, Coleman J, Melia TJ, Giraudo CG (2011) Dual roles of Munc18-1 rely on distinct binding modes of the central cavity with Stx1A and SNARE complex. Mol Biol Cell 22: 4150-4160

Sørensen JB (2009) Conflicting views on the membrane fusion machinery and the fusion pore. Annu Rev Cell Dev Biol 25: 513-537

Südhof TC, Rizo J (2011) Synaptic vesicle exocytosis. Cold Spring Harb Perspect Biol 3: a005637

Südhof TC, Rothman JE (2009) Membrane fusion: grappling with SNARE and SM proteins. Science 323: 474-477

Sun J, Pang ZP, Qin D, Fahim AT, Adachi R, Südhof TC (2007) A dual- $\mathrm{Ca}^{2+}$-sensor model for neurotransmitter release in a central synapse. Nature 450: 676-682

Sutton MA, Schuman EM (2009) Partitioning the synaptic landscape: distinct microdomains for spontaneous and spike-triggered neurotransmission. Sci Signal 2: pe19
Tareste D, Shen J, Melia TJ, Rothman JE (2008) SNAREpin/Munc18 promotes adhesion and fusion of large vesicles to giant membranes. Proc Natl Acad Sci USA 105: 2380-2385

Verhage M, Maia AS, Plomp JJ, Brussaard AB, Heeroma JH, Vermeer $\mathrm{H}$, Toonen RF, Hammer RE, van den Berg TK, Missler M, Geuze HJ, Südhof TC (2000) Synaptic assembly of the brain in the absence of neurotransmitter secretion. Science 287: 864-869

Yamaguchi T, Dulubova I, Min SW, Chen X, Rizo J, Südhof TC (2002) Sly1 binds to Golgi and ER syntaxins via a conserved N-terminal peptide motif. Dev Cell 2: 295-305

Yang X, Kaeser-Woo YJ, Pang ZP, Xu W, Südhof TC (2010) Complexin clamps asynchronous release by blocking a secondary $\mathrm{Ca}^{2+}$ sensor via its accessory $\alpha$ helix. Neuron 68: 907-920 